\title{
E-Books Preference Compared to Print Books Based on Student Perceptions: A Case of University of Fort Hare Students
}

https://doi.org/10.3991/ijim.v13i12.10840

\author{
Comfort Makwanya ${ }^{(凶)}$, Olabanji Oni \\ University of Fort Hare, East London, South Africa \\ comfortmakwanya@gmail.com
}

\begin{abstract}
Technology advent has been transforming students' perceptions and preferences mostly on how they acquire information and learn. The way students perceive e-books and print books significantly influences the format they prefer to use for academic purposes. Recently, the accessibility of e-books on assorted mobile gadgets is substituting the conventional print based resources which are regarded costly in production, sharing and also heavy. Differing views on the format (e-book or print) that students prefer for academic purposes to improve their educational experience exist of which most studies have been done in developed countries. Therefore, a research that reveals students' perceptions and preferences towards the two book formats in the nation of South Africa can afford a better understanding and conclusion on an African student. This study aimed to determine students' preference on using e-books and print books in meeting academic information needs based on perceptions. The study adopted a cross-sectional research design and a questionnaire as a research instrument which was administered to students at the University of Fort Hare. Findings revealed that students preferred using both (e-books and print books) for their academic needs. Moreover, they perceived e-books to be as good as print books, easy and friendly to use and capable of providing sufficient information to meet educational needs.
\end{abstract}

Keywords-E-books, print books, student perceptions, student preferences, University of Fort Hare.

\section{Introduction}

Innovation on technology is rising each day with new technologies changing students' way of life from how they communicate, play, and socialize up to how they learn. Internet penetration in everyday life is altering students' reading patterns and behavior, this then compels students to further integrate the use of technology in their academic lives [1]. E-books are a reality that will surpass the education marketplace and in the long run completely alter the distribution and accessibility of information. Such a change is attributed to the major benefits that e-books have over their print counterparts which are accessibility and flexibility[2]. Technology offers a huge potential to advance learning as it has been established to improve learning outcomes 
and learner engagement [3]. An evolving need therefore exists for stakeholders to benefit from this technology increase, as it presents an opportunity to improve learning through the substantial information offered by the internet [1].

E-books are defined as any form of publication that exists in electronic format and is read on an electronic device, while a print book is text that is read on a paper [4]. It is said that, "in general, e-books are defined as digitised versions of the paper-based book that can be delivered on a variety of electronic platforms, ranging from personal computers to mobile devices" [5]. A print book on the other hand is, "a set of written, printed or blank sheets bound together between a front and back cover" [6]. E-books are becoming students' favorite for they are portable, compatible with internet devices, convenient, searched easily, less expensive, less weight and provides remote access [7]. Additionally, their visual appeal such as graphics, video clips and features that include supportive material, audio, links to activities, and websites make them more appealing to users than print books. It is therefore critical to evaluate the essence of e-books as learning tools before they can be ultimately be integrated and recommended as substitutes of print books [8].

Digital technology is transforming and disrupting the print media or the textbook industry in the form of e-books; publishers, retailers, and content owners are cautioned to be proactive in securing places in the e-book market or else lose out in this new industry as the traditional print is gradually being replaced by digital [9]. [10] Further states that, with the universal spread of mobile devices, it is crucial to study the benefits that they bring to teaching and learning environments. This study, therefore, sought to investigate e-books preference compared to print books based on student perceptions; a case of University of Fort Hare students. Comprehension of students' needs and preference in terms of academic reading purposes facilitates proper development of appropriate learning tools and allows for the designing of standardized reading material [11]. Such an understanding of students' preference will consequently lead to improved student engagement and improved learning outcomes.

\section{Literature Review}

Internet advancement and subsequently digital text has brought about rapid change in all areas of life. Individuals are now used to producing, writing, storing and retrieving documents electronically on a wide range of electronic devices. E-books are noted to be receiving more attention from more readers and individuals within the industry [12]. The popularity of tablets and electronic readers in South Africa has been predicted to increase spending on e-books and cut into print book sales [8]. It has been noted that students' information seeking behavior has changed in universities, students are now preferring almost everything in digital form [13]. Given this background, the old-style print book can seem to be under threat as students will resultantly expect electronic access to their study material the same way they access other things online [14]. Students are faced with a dilemma of either using e-books or print books. The critical question in this circumstance is, will e-books absolutely replace print books? This dilemma has warranted diverse studies that try and explain the fu- 
ture of print considering the massive rate at which e-books are being published and adopted.

Regardless of efforts by libraries, perceptions on e-books and print books significantly vary with student. The advantages and disadvantages associated with each format influences perception, preference and adoption by each student [15]. Some educational institutions have gone to the extent of making e-books and other electronic resources their preferred choice of study tools, however accessible research does not prove that students actually favor e-books over print books. This is so because the two formats possess unique abilities in meeting consumers' needs thereby should complement each other rather than substituting.

Students generally prefer e-books because they perceive them as cheap, light, convenient and enable the storing of all the course material in a single unit rather than carrying different heavy print books [16], [17]. E-books are also perceived to improve learning experience if they are successfully incorporated in learning environments especially for students with disabilities and long distance students [18]. In [19], ebooks are said to have become popular in the community and are read from a range of devices. The accessibility of e-textbooks on a wide range of mobile devices have given an alternative to the expensive and heavy print resources.

The university students investigated by [15] showed a very strong preference for print books as reinforced by the move to print part of the academic electronic titles they would want to read. Mobile devices and computers were the preferred devices when reading e-books, but for academic purposes students preferred to print part of them when reading [20]. Results indicate that though the majority of respondents indicated that they preferred print books to e-books, they however liked the convenience that the electronic format gives [21].

Even though some institutions made decisions to make e-textbooks and other electronic resources the preferred method to students, research doesn't show that students in actual fact favour e-textbooks over print [19]. Despite the fact that the bulk of prevailing reader researches have made suppositions concerning the end of the common print format, several studies have failed to survey thoroughly readers who decide to utilise both formats. Such users can really offer a comparative intuition especially into what readers prefer [22]. Understanding that today's consumers have expectations such as immediate, easy and economical access of information makes publishers to improve their ability to serve them.

Consumers are not mainly concerned with discriminating format between digital and non-digital in delivery, they are concerned with their needs being met by the format. In this case understanding which format students prefer will fulfil the goal of consumer satisfaction by both libraries and publishers [13]. 


\section{$3 \quad$ Research Methodology}

\subsection{Research design}

The study followed a descriptive research design to describe the data, selfadministered questionnaires were used as the data collection instrument. Data was gathered from the University of Fort Hare students in the Faculty of Management and Commerce. The participants were drawn through convenience sampling and 200 complete responses were generated. The Cronbach's alpha value for the 30-item research instrument was 0.7770 which showed high reliability coefficients for the research instrument. This is in line with the recommended Cronbach's alpha value of more than 0.7 which shows more reliability of the instrument [23]. The questionnaire was comprised of two sections, the first section contained questions relating to demographic information such as age, gender, level of study and awareness. In the second section perceptions and preference on e-books and print books were determined by using a 5 point Likert scale (1 (highest) to 5 (lowest)) where respondents ranked their level of agreement with 1 representing strongly agree, 2 agree, 3 neutral, 4 disagree and 5 strongly disagree.

\subsection{Data analysis}

Statistical Package for Social Sciences (SPSS) version 25 software was used for data analysis. Variables were tested for the significance of the relationship using the Pearson Chi-Square test which was also used in other studies that investigated student perceptions of e-books [11]. A non-parametric Chi-square test was also opted for comparisons on how the respondents responded to the various items regarding the perception and preference of respondents on electronic and print books.

\section{$4 \quad$ Findings}

The 5-point Likert scale (Strongly Agree (SA), Agree (A), Neutral (N), Disagree (D) and Strongly Disagree (SD) was collapsed to Agree (A), Neutral (N) and Disagree (D). This was done by means of combining Strongly Agree (SA) and Agree (A) as well as combining Disagree (D) and Strongly Disagree (SD). A chi-square test for equal proportions was then elected to compare responses for each question.

To determine students' perceptions towards e-books and print books, the majority of respondents (Agree $=61.0 \%$ ) perceived it to be easier to use e-books for research purposes rather than print books (Chi-square $=70.810 ; \mathrm{df}=2 ; \mathrm{p}=<0.0001$ ). Also, (Agree $=61.5 \%$ ) of respondents shared the view that e-books are as good as print books (Chi-square $=71.590 ; \mathrm{df}=2 ; \mathrm{p}=<0.0001)$. However, most students significantly disagreed to the fact that the library should continue to purchase electronic books only and not purchase print books (Chi-square $=38.770 ; \mathrm{df}=2 ; \mathrm{p}=<0.0001$ ) as well as that the library should continue to purchase print books only and not buy electronic books (Chi-square $=51.160 ; \mathrm{df}=2 ; \mathrm{p}=<0.0001)$. This shows that students 
want both formats for their academic studies and not the extinction of either. Most respondents (Agree $=46.5 \%$ ) shared the sentiment that electronic books will ultimately cause the disappearance of the traditional print books (Chi-square $=51.160 ; \mathrm{df}=2$; $\mathrm{p}=<0.0001)$.

In determining preference, the results show that, the majority of respondents (44.0\%) prefer both print and e-books as compared to print books only (34.5\%) and electronic books only (21.5\%). It can then be concluded that when students are given to choose between print books and e-books they prefer print books but in the instance where they are given the third option of both formats students preferred the combination of the two formats for academic study. This is shown in Fig. 1.

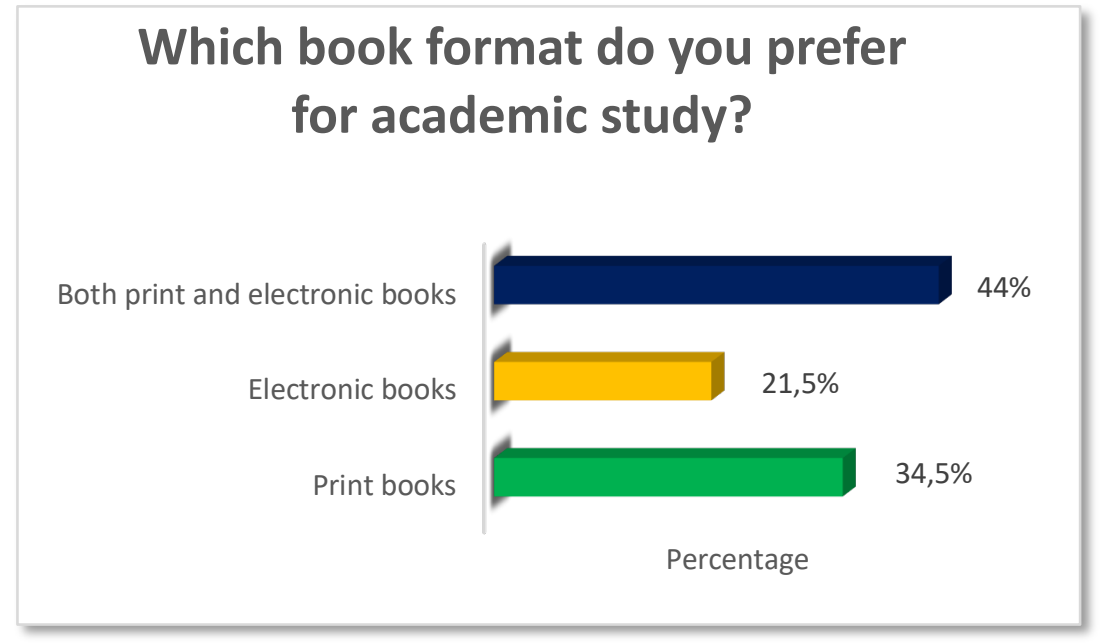

Fig. 1. Preferred format

Respondents were also requested to indicate their level of agreement on statements that related to their preference and perceptions on both print and electronic books. There was a strong indication from the data gathered in the study that most students prefer using electronic books for information needs over printed books (Chi-square $=$ 35.497; $\mathrm{df}=2 ; \mathrm{p}=<0.0001)$ and also that they consider electronic books capable of providing adequate information to meet information needs (Chi-square $=89.075$; $\mathrm{df}=$ $2 ; \mathrm{p}=<0.0001)$.

Table 1. Respondents responses regarding their preferences in terms of both print and e-books

\begin{tabular}{|l|c|c|c|c|c|}
\hline \multicolumn{1}{|c|}{ Do you agree with the following statements } & D & N & A & $\begin{array}{c}\text { Chi- } \\
\text { Square }\end{array}$ & p-value \\
\hline $\begin{array}{l}\text { Item 1: I prefer using electronic books for my information } \\
\text { needs over printed books }\end{array}$ & $30.7 \%$ & $17.6 \%$ & $51.8 \%$ & 35.497 & $\begin{array}{c}<0.0001 \\
*\end{array}$ \\
\hline $\begin{array}{l}\text { Item 2: I consider electronic books capable of providing ade- } \\
\text { quate information to meet my study needs }\end{array}$ & $16.1 \%$ & $19.1 \%$ & $64.8 \%$ & 89.075 & $\begin{array}{c}<0.0001 \\
*\end{array}$ \\
\hline
\end{tabular}

$\mathrm{N}=200$, Statistically significant differences $(* \mathrm{p}<.05)$. 
It was necessary to check if a linear relationship existed between the study's main theoretical variables. In achieving this, the Spearman Rho correlation coefficient (two-tailed test) was used. The results suggested that preference of e-books have a positive and significant relationship with e-book use $(r=0.234 ; \mathrm{p}=0.001)$ and perceptions on e-books $(\mathrm{r}=0.272 ; \mathrm{p}=<0.0001)$. Usage of e-books had a moderate, positive and significant correlations to level of study $(r=0.300 ; p=<0.0001)$. There were no significant correlations between preference of e-books and usage of e-books $(r=$ $0.115 ; \mathrm{p}=0.105)$ as well as level of study $(\mathrm{r}=0.017 ; \mathrm{p}=0.813)$. Perceptions on ebooks was however positively correlated with the level of study $(r=0.157 ; p=$ 0.026). It can be concluded that perceptions on e-books and usage of e-books influences the preference on e-books, perceptions and the level of study were also found to be correlating. However, no significant relationship exists between preference, use and level of study.

\section{Discussion}

The study aimed to determine student perceptions with regards to the use of ebooks and print books in meeting educational needs. A variety of studies investigated the perceptions that are held by students towards e-books. This present study found out that the majority of students $(61.0 \%)$ perceived it easier to use e-books for research than print books. In another question, most of the students had the view that electronic books were as good as print books. Findings also show that students consider e-books capable of providing adequate information to meet their study needs.

The findings of this study concur with the findings by [24] that highlight that the majority of the students investigated had a positive perception of e-books. Investigated students perceived a better acquisition of skills and an intensified internalization of positive attitudes towards the subject content. Another study's results also indicated that students who used e-books had a higher perceived affective and psychomotor learning than students who used traditional print books [25]. A similar study also reported strong perceptions by students. They responded that using an e-reader helps them to connect ideas in new ways, aids them to take part in the course activity to enhance learning, and assists in application of course material to solve problems. Students also reported that e-books enable them to easily search and share information [5]. Majority of the respondents also regarded the 24/7 access and availability, remote access, a range of titles to choose from, search tools, speed and convenience as attributes of the positive perception that they had towards e-books. Conclusively, student perceptions vary from study to study being influenced by factors such as awareness, previous use and the university policy towards e-books.

The study also aimed to determine the preference between e-books and print books when gathering information. The current study gave an opportunity for respondents to choose their preference between print, e-books and an option for both formats. The findings on the preferences of both print and e-books by the respondents show that there was a strong preference for both formats by most students. It further revealed that the majority of students prefer both print and e-books as compared to print books 
only and e-books only. Between the two options of print and e-books only, print books scored higher than e-books. Also students responded that they prefer using ebooks for study needs over printed books.

The results from this study that students prefer print books when studying concur with some of the studies that highlight that students preferred print books over ebooks despite the popularity of interactive technology and computers in their lives, sighting convenience and ease of reading of print compared to screens as the main reasons [26]. It was also discovered that parents of pupils investigated by [27] conveyed a strong preference for print books use by their children. A similar investigation on the University of Malawi College, discovered that students used both formats, but print books were more used than electronic formats with most students $(60.6 \%)$ preferring print textbooks [20]. A printed book was also concluded to be the most popular text book among students, with the results showing some degree of uncertainty amongst students on which book format they prefer print or e-books. This however was accounted for by the authors as the inadequate exposure to e-book features and capabilities [28]. These results corroborate with similar findings from these studies that stress students' reluctance to exclude print text format from their studies.

When it comes to adding both formats as a choice, students in this study indicated that they prefer to use both formats. This is in line with findings by [22] that, when it came to comparing the three options, the option of reading both e-books and print books scored much higher than print or e-books alone. Similarly, [5] established that using both formats was the most popular response of those who were surveyed. Results by [29] show that the highest number of students preferred to have both formats, an electronic textbook and a printed textbook. Surprisingly, [30] discovered that the largest portion of students responded that they did not care which format the library purchased. As a result, the conclusion drawn is that the participants are comfortable with both methods and the format does not matter much to them, what matters is the ability to meet academic needs.

\section{Conclusion}

This study paid much attention to perceptions and preferences of students regarding e-books and print books. For future research, the researcher suggests the employment of an experimental research in order to determine a cause and effect relationship between variables. Longitudinal research is also needed so as to track the change in students' preference and perceptions towards e-books and ultimately their adoption rate. As e-reader platforms are developing in the South African market, more research is needed on the changing student perceptions especially on the efficacy of utilising diverse digital media in e-books over the use of print books. Repeated research can also bring about comparative interpretations from different settings for example on a local, national and international context.

The discussion on findings indicated that students had positive perceptions towards e-books and ultimately preferred both formats (print and e-book) to meet their information need requirements. The results of this study indicated that students have di- 
verse preferences for book format. It is then recommended that all practitioners should be hands on to enable awareness and the provision of e-book resources that are tailor made to meet reader's information needs if they are to enhance the teaching and learning process.

The question remains, when students read e-books, do they end up getting used to them, discover the benefits they have and resultantly become interested and start using them? Since libraries are restricted by budgetary costs, they are not able to acquire all books in every format, which means some users will have to read on a medium that won't be their preferred medium. Considering that ownership of tablets and mobile gadgets is rapidly increasing, libraries should make efforts in purchasing more ebooks than print books. If e-books are easily accessible to students then preference for them might become ultimate.

\section{$7 \quad$ References}

[1] M. Weisberg, "Student attitudes and behaviors towards digital textbooks," Publ. Res. Q., vol. 27, no. 2, pp. 188-196, 2011. https://doi.org/10.1007/s12109-011-9217-4

[2] F. Okite-Amughoro, L. Makgahlela, and S. Bopape, "Challenges of Using Electronic Information Resources for Academic Research By Post- Graduate Students At Delta State University, Abraka, Nigeria," vol. 33, no. 4, pp. 23-37, 2015. https://doi.org/10.7553/80-2$\underline{1527}$

[3] Z. Karabatzaki et al., "Mobile Application Tools for Students in Secondary Education. An Evaluation Study.," Int. J. Interact. Mob. Technol., vol. 12, no. 2, p. 142, 2018.

[4] A.-L. Davidson and S. Carliner, "E-books for educational uses," Handb. Res. Educ. Commun. Technol., pp. 713-722, 2014.

[5] E. Mulholland and J. Bates, "Use and Perceptions of E-books by Academic Staff in Further Education,” J. Acad. Librariansh., vol. 40, no. 5, pp. 492-499, 2014. https://doi.org/ 10.1016/j.acalib.2014.05.018

[6] Merriam-webster, “Book," 2018. [Online]. Available: https://www.merriamwebster.com/dictionary/book. [Accessed: 14-Jul-2018].

[7] N. K. Malhotra and D. Birks, Marketing Research,An Applied Approach, 3 European. Financial Times - Pearson - Prentice Hal, 2007.

[8] W. D. Woody, D. B. Daniel, and C. A. Baker, "E-books or textbooks: Students prefer textbooks," Comput. Educ., vol. 55, no. 3, pp. 945-948, 2010. https://doi.org/10.1016/j.comp edu.2010.04.005

[9] PricewaterhouseCoopers, “Annual Report 2010//2011,” 2010.

[10] J. Bidarra, M. Figueiredo, and C. Natálio, "Interactive Design and Gamification of eBooks for Mobile and Contextual Learning," Int. J. Interact. Mob. Technol., vol. 9, no. 3, p. 24, 2015. https://doi.org/10.3991/ijim.v9i3.4421

[11] K. A. Sheen and Y. Luximon, "Student perceptions on future components of electronic textbook design,” J. Comput. Educ., vol. 4, no. 4, pp. 371-393, 2017. https://doi.org/10.10 07/s40692-017-0092-7

[12] Y. S. Choi and L. Up, "Contextual Factors Affecting the Innovation Performance of Manufacturing SMEs in Korea : A Structural Equation Modeling Approach,” Dep. Urban Plan. Eng., vol. 9, no. July, pp. 1193-2001, 2017. https://doi.org/10.3390/su9071193

[13] K. N. Rao, M. Tripathi, and S. Kumar, "Cost of Print and Digital Books: A Comparative Study,” J. Acad. Librariansh., vol. 42, no. 4, pp. 445-452, 2016. 
[14] G. Berisha and J. S. Pula, "Defining Small and Medium Enterprises : a critical review," Acad. J. Business, Adm. Law Soc. Sci., vol. 1, no. 1, pp. 16-28, 2015.

[15] U. Omeluzor, A. Akibu, and A. Akinwoye, "Students' Perception, Use and Challenges of Electronic Information Resources in Federal University of Petroleum Article," Libr. Philos. Pract., no. November, p. 1428, 2016.

[16] M. McGowan, P. Stephen, and C. Bradley, "Student perceptions of electronic textbooks," Issues Inf. Syst., vol. 10, no. 2, pp. 459-465, 2009.

[17] M. Millar and T. Schrier, "Digital or Printed Textbooks: Which do Students Prefer and Why?" J. Teach. Travel Tour, vol. 15, no. 2, pp. 166-185, 2015. https://doi.org/10.1080/ 15313220.2015 .1026474

[18] H. Woodward, Ebooks in education: Realising the vision. London: Ubiquity Press, 2014.

[19] R. Martin, "The road ahead: eBooks, eTextbooks and publishers' electronic resources," ASCILITE-Australian Soc. Comput. Learn, no. 2010, pp. 2008-2012, 2012.

[20] G. Dalmarco, A. Eduardo, M. Trevisan, and J. Mortari, "The use of knowledge management practices by Brazilian startup companies," RAI Rev. Adm. e Inovação, vol. 14, no. 3, pp. 226-234, 2017. https://doi.org/10.1016/j.rai.2017.05.005

[21] S. Wang and X. Bai, "University Students Awareness, Usage and Attitude Towards Ebooks: Experience from China,” J. Acad. Librariansh., vol. 42, no. 3, pp. 247-258, 2016. https://doi.org/10.1016/j.acalib.2016.01.001

[22] Y. Zhang and S. Kudva, "E-books versus print books: Readers' choices and preferences across contexts," J. Assoc. Inf. Sci. Technol., vol. 65, no. 8, pp. 1695-1706, 2014. https:// doi.org/10.1002/asi.23076

[23] P. Panayides, "Coefficient alpha: Interpret with caution,” Eur. J. Psychol., vol. 9, no. 4, pp. 687-696, 2013. https://doi.org/10.5964/ejop.v9i4.653

[24] L. Muir and G. Hawes, "The Case for e-Book Literacy: Undergraduate Students' Experience with e-Books for Course Work," J. Acad. Librariansh., vol. 39, no. 3, pp. 260-274, 2013. https://doi.org/10.1016/j.acalib.2013.01.002

[25] A. J. Rockinson- Szapkiw, J. Courduff, K. Carter, and D. Bennett, "Electronic versus traditional print textbooks: A comparison study on the influence of university students' learning," Comput. Educ., vol. 63, pp. 259-266, 2013. https://doi.org/10.1016/j.compedu.2012. $\underline{11.022}$

[26] D. Mawindo and R. Hoskins, "Use Of Print And Electronic Resources," vol. 25, no. 1, pp. 89-110, 2008.

[27] K. T. See, B. H. Madhubala, and A. C. Koo, "Motivation of Parents Towards Reading Multilingual eBooks To Pre-School Children,” pp. 20-36. https://doi.org/10.3991/ijim.v13 i01.9060

[28] A. Khalid, "Text books: Ebook Vs. Print," J. Educ. Hum. Dev., vol. 3, no. 2, pp. 243-258, 2014.

[29] M. Wiese and G. Du Plessis, "The battle of the e-textbook: Libraries' role in facilitating student acceptance and use of e-textbooks," South African J. Libr. Inf. Sci., vol. 80, no. 2, pp. 17-26, 2015. https://doi.org/10.7553/80-2-1509

[30] H. Sulistyo, “Asia Paci fi c Management Review Innovation capability of SMEs through entrepreneurship , marketing capability , relational capital and empowerment," Asia Pacific Manag. Rev., vol. 21, no. 4, pp. 196-203, 2016. https://doi.org/10.1016/j.apmrv.2016. $\underline{02.002}$ 


\section{Authors}

Comfort Makwanya is a Masters graduate student at the University of Fort Hare in the Faculty of Management and Commerce and the Department of Business Management.

Olabanji Oni is a professor and a lecturer at the University of Fort Hare in the Faculty of Management and Commerce and the Department of Business Management. Address: University of Fort Hare, East London Campus, 50 Church Street, East London, 5201

Article submitted 2019-05-10. Resubmitted 2019-06-28. Final acceptance 2019-07-10. Final version published as submitted by the authors. 